\title{
A construção de um novo "espírito" do capitalismo em uma sociedade em rede*
}

\author{
The construction of a new capitalism \\ "spirit" in a networked society
}

\author{
Daniel Coelho de Oliveira* \\ Thiago Augusto Veloso Meira*2
}
Palavras- Resumo: O artigo objetiva construir uma ponte entre o que se chaves: convencionou denominar de "primeiro espírito do capitalismo", a Capitalismo;
Redes; partir das proposições teóricas presentes na obra de Max Weber, e o Poder. "novo" espírito do capitalismo, na concepção de Luc Boltanski e Ève Chiapello e da "Sociedade em Rede" de Manuel Castells. De maneira analítica, serão realizadas convergências e aproximações metodológicas entre as abordagens de Boltanski, Chiapello e Castells.

Keywords: Capitalism; Network; Power.

\begin{abstract}
The paper aims to build a bridge between what is conventionally called the first spirit of capitalism from the theories proposed in the work of Max Weber, and the "new" spirit of capitalism as set forth by Luc Boltanski and Ėve Chiapello, and the "network society" proposed by Manuel Castells. We will analyze the convergences and methodology in the way Boltanski, Chiapello, and Castells approach the issue.
\end{abstract}

\footnotetext{
* Artigo recebido em 26/09/2012 e aprovado para publicação em 07/02/2013.

*1 Professor do Departamento de Ciências Sociais da Universidade Estadual de Montes Claros (UNIMONTES). Mestre e doutorando em Ciências Sociais pelo CPDA/UFRRJ.

*2 Professor da Universidade Estadual de Montes Claros. Mestre em Política Social pela Universidade Federal Fluminense, Rio de Janeiro. E-mail: daniel.coelhoo@yahoo.com.br.
} 


\section{Apresentação}

“T movo espectro ronda o mundo: espectro da rede." Esta poderia ser a frase do "Novo Manifesto do Partido Comunista" se Karl Marx ainda estivesse entre nós. O capitalismo tem se mostrado com uma imensa capacidade de adaptar-se a novos contextos. Seu poder poderia ser chamado de transformador adaptativo. Transformador, porque o foi desde a sua origem, solapando as bases de um tradicionalismo construído durante séculos. Adaptativo, pois além de se acomodar nas mais diversas estruturas culturais impeliu quase a totalidade das nações a sua lógica de reprodução.

Sem nenhum fatalismo, o capitalismo se perpetuou até o momento, sendo duro quando se permitiu e flexível quando conveniente, sem nunca se esquecer, por outro lado, de motivar todos os seus adeptos a um engajamento profundo.

O presente trabalho passa por uma tentativa de construir uma ponte entre o que se convencionou denominar "primeiro espírito do capitalismo", a partir das proposições teóricas presentes na obra de Max Weber, e o "novo" espírito do capitalismo, na concepção de Boltanski e Chiapello (2009) e ainda a "Sociedade em Rede" de Castells (1999). O artigo será estruturado da seguinte forma: nas duas seções iniciais, apresentar-se-á de maneira descritiva o que se entende por primeiro espírito do capitalismo, o novo espírito do capitalismo e a sociedade em rede. Em seguida, de forma analítica, serão realizadas convergências e aproximações metodológicas entre as abordagens de "O novo espírito do capitalismo" e a "Sociedade em Rede", tendo em vista um melhor delineamento das posições defendidas pelos autores. A dinâmica do "poder" dentro da estrutura das redes será explorada na quarta seção. O "tempo" aparecerá na quinta seção como variável importante para entender o espírito do capitalismo na sociedade em rede. Ao final do artigo, serão costuradas algumas considerações de caráter não conclusivo.

\section{Do velho ao novo espírito do capitalismo}

Logo no início de sua obra, Weber (2004) formula uma problematização de ordem estatística. Segundo ele, ao observar as estatísticas ocupacionais em alguns países europeus, é possível constatar a notável frequência de um fenômeno, o caráter predominantemente protestante dos proprietários de capitais e empresários, assim como das camadas superiores da mão de obra qualificada. A maior participação de protestantes em postos de trabalhos mais elevados nas grandes empresas 
capitalistas se deve em parte a razões históricas. Retomando o passado, percebe que a confissão religiosa não aparece como causa, mas sim como consequência de fenômenos econômicos.

Weber (2004) aponta a Reforma Protestante como importante fato histórico. Não no sentido de eliminar a dominação, mas pela substituição de uma dominação extremamente cômoda da Igreja Católica que penetrou e procurou regular todas as esferas da vida doméstica e pública. Na concepção de Giddens (1990), a novidade da obra de Weber não consiste em fazer uma relação entre a Reforma e o capitalismo moderno. Autores anteriores a Weber já haviam feito essa relação, como foi o caso de alguns escritos de Marx e Engels. Sua originalidade é constituída a partir do entendimento que protestantismo, longe de se desinteressar do controle das atividades cotidianas, exigia de seus fiéis uma disciplina muito mais rígida do que o catolicismo, introjetando assim um elemento religioso em todos os aspectos da vida do crente.

O espírito do capitalismo atual não é o mesmo de sua origem. O primeiro, materializado na obra de Max Weber, dava especial valor à moral da poupança; já no segundo, o que predomina é a moral do trabalho e da competência. O "novo" espírito do capitalismo se apoia no desenvolvimento que Boltanski e Chiapello (2009) denominaram "mundo conexionista" ou "cidade dos projetos".

No fim dos anos 1960 e início dos 1970 o capitalismo sentiu a redução do crescimento e rentabilidade. Por outro lado, a sua crítica estava no auge, como demonstrou os acontecimentos de maio de 1968 na França. Após a segunda metade da década de 1970, o que se observou foi o sumiço repentino da crítica, deixando um espaço livre para a reorganização do capitalismo nas duas décadas seguintes. Seu papel se limitou ao registro das crescentes dificuldades do corpo social.

Parece-nos útil, para tanto, abrir a caixa-preta dos últimos trinta anos e olhar o modo como os homens fazem sua história. Voltando para o momento em que as coisas se decidem e mostrando que elas poderiam ter enveredado por direção diferente, a história constitui o instrumento por excelência da desnaturalização do social e está de mãos dadas com a crítica (BOLTANSKI; CHIAPELLO, 2009, p. 29).

A partir dessas inquietações iniciais, Boltanski e Chiapello (2009) propõem analisar as mudanças ideológicas que acompanharam as recentes transformações do capitalismo. O recorte temporal da obra abrange os acontecimentos de maio de 1968 aos anos 1980, até a segunda metade da década de 1990. O espaço da pesquisa é a França - os autores defendem 
que há boas razões para acreditar que os acontecimentos vivenciados no país, em boa medida, representam as mudanças ideológicas que ocorrem na reestruturação do capitalismo em outros países. Mais do que uma obra descritiva, é proposto um quadro teórico, cuja finalidade é de compreender a forma que se transformam as ideologias relacionadas às atividades econômicas. Boltanski e Chiapello (2009) são enfáticos ao afirmar que o conceito de ideologia não é empregado no sentido redutor, em certa medida vulgarizado pelos marxistas. Pretende-se empregá-lo como "conjunto de crenças compartilhadas, inscritas em instituições, implicadas em ações e, portanto, ancoradas na realidade" (BOLTANSKI; CHIAPELLO, 2009, p. 33). A ideologia seria responsável por formar a base de justificação do "novo" espírito do capitalismo.

Ao falar de espírito do capitalismo, Weber (2004) não utiliza o termo de modo genérico. Trata-se apenas de um "espírito" capitalista da Europa Ocidental e da América do Norte, pois o "Capitalismo" já existiu na China, na Índia, na Babilônia, na Antiguidade e da Idade Média. Mas nesses outros exemplos históricos faltava-Ihe precisamente esse éthos peculiar. Mas qual seria a oposição do espírito capitalista? O principal adversário contra o qual o espírito do capitalismo teve de lutar foi o comportamento que se pode chamar de tradicionalismo. O exemplo de uma atitude tradicionalista pode ser observado em um homem que não se perguntava quanto pode ganhar por dia se render o máximo no trabalho, mas quanto deve trabalhar para ganhar a mesma quantia. O Capitalista da ética protestante não eram especuladores temerários e sem escrúpulos, aventureiros econômicos, nem ricos agentes. Eram "homens criados na dura escola da vida, a um só tempo audazes e ponderados, mas, sobretudo, sóbrios e constantes, sagazes e inteiramente devotados à causa, homens com visões e 'princípios' rigorosamente burgueses" (WEBER, 2004, p. 2004).

A noção de "espírito do capitalismo" é utilizada por Boltanski e Chiapello (2009) porque ela permite que os conceitos de capitalismo e sua crítica sejam relacionados de forma dinâmica. A necessidade de um "espírito" para o capitalista advém da própria incoerência do sistema, fato que justifica colocar a noção de "espírito" no centro da análise. $\mathrm{Na}$ atualidade, nota-se que os trabalhadores assalariados estão destituídos do resultado do seu trabalho e, como consequência, são incapazes de levar uma vida digna e independente. O valor que recebem pela venda de sua força de trabalho constitui no máximo uma razão para ficar no emprego e não para dedicar-se a ele. Em outra ponta, os capitalistas estão inseridos em um processo sem fim e abstrato de acumulação, totalmente desvinculado das necessidades de consumo, mesmo as mais supérfluas. Como pensar o 
engajamento pessoal em um sistema que não se justifica pelos seus resultados materiais? Boltanski e Chiapello (2009) chamam de espírito do capitalismo a ideologia que justifica o engajamento no capitalismo. Para ocorrer o engajamento "O capitalismo precisa ter condições de dar a essas pessoas a garantia de uma segurança mínima em verdadeiros santuários onde é possível viver, formar família, criar filhos etc." (BOLTANSKI; CHIAPELLO, 2009. p. 39).

O capitalista originário da ética protestante apresentava atitudes, aparentemente, irracionais que geraram uma conduta de vida racional. Para Weber (2004), o calvinismo ${ }^{1}$ defendia uma desumanidade patética, como foi o caso da doutrina da predestinação. Porém, o efeito foi uma mudança radical na condução da vida intramundana de seus membros. A santificação da vida no calvinismo assemelhava-se ao caráter de administração de empresa. O comportamento ascético tomava conta de toda a existência do indivíduo. A metódica conduta de vida ética influenciada pelo calvinismo contrastava com a posição do catolicismo e do luteranismo.

E com mais razão o catolicismo considerou o calvinismo, desde o início até os dias de hoje, como seu verdadeiro adversário [...] Mas a razão dessa repulsa comum aos católicos e luteranos se funda na peculiaridade ética do calvinismo. Já uma vista de olhos superficial nos ensina que aqui se produziu uma relação entre vida religiosa e ação terrena de espécie totalmente diversa das que produziram, quer no catolicismo quer no luteranismo (WEBER, 2004, p. 78-79).

A desvinculação da possibilidade de salvação por intermédio da Igreja e dos sacramentos constitui a principal diferença dos calvinistas em relação a católicos e luteranos. Para a igreja de Calvino, a responsabilidade de

\footnotetext{
${ }^{1}$ Apesar das importantes transformações, introduzidas pelo luteranismo, Weber (2004) não as considera propulsoras do espírito capitalista. Existiram outras religiões protestantes, com destaque para o protestantismo ascético. Weber divide o protestantismo ascético em quatro correntes: calvinismo, metodismo, pietismo e as seitas nascidas do movimento anabatista. Trata-se de seitas que tiveram um relacionamento muito próximo entre si, não sendo possível fazer uma distinção clara entre elas. O calvinismo recebe uma atenção especial na análise, por representar a vertente protestante que foi mais eficaz na condução metódica de vida de seus fiéis. As igrejas calvinistas fazem parte do chamado protestantismo reformado. Assim como o luteranismo, o calvinismo defende a autoridade soberana das Escrituras, mas se distancia da confissão luterana ao enfatizar a onipotência de Deus. Se por um lado existe a glória divina por outro há a corrupção humana. É, nesse contexto, que Calvino apresenta a ideia de predestinação, segundo a qual Deus, desde o princípio do mundo, destinou uns à salvação e outros à condenação dos infernos (REEBER, 2002). De acordo com Weber (2004), a doutrina da predestinação é o mais característico dogma do calvinismo. Segundo a mesma, não é Deus que existe para os seres humanos, mas os seres humanos que existem para Deus e somente uma parcela dos homens é chamada à bem-aventurança eterna - a outra parte será condenada.
} 
salvação dependia da conduta mundana; o fiel se via relegado a percorrer sozinho a estrada rumo ao encontro do seu destino na eternidade. Portanto, - calvinismo encerra um grande processo histórico, 0 gradual "desencantamento do mundo".

Como foi possível verificar, o principal mérito da ética protestante consiste no fato de ela ter demonstrado que o instrumentalismo moral do espírito do capitalismo constituiu consequência involuntária de uma ética religiosa. Ou seja, que havia afinidade entre certas denominações protestantes e a ética econômica da atividade capitalista moderna. Demonstrou-se, assim, que a racionalização da vida econômica que caracteriza o capitalismo moderno se relaciona com compromissos de valores irracionais.

Observa-se que os três pilares que justificam o novo espírito capitalista são: eficiência na satisfação das necessidades, eficácia e progresso material. Mas por se tratar de aspectos genéricos e por ser estáveis no tempo, tais razões não parecem suficientes para engajar a maioria das pessoas no mundo do trabalho capitalista. Boltanski e Chiapello (2009) ressaltam que o discurso empresarial é a maneira com a qual o espírito do capitalismo é incorporado e apresentado como algo que deve ser compartilhado por todos. Tal discurso tem com principal alvo os executivos, cuja adesão ao capitalismo é essencial para o bom funcionamento das empresas. Há também a preocupação de que os filhos da burguesia não "desertem", pois eles são o "viveiro" natural para futuros recrutamentos. 0 capitalismo não encontra em si mesmo nenhum motivo que justifique o engajamento.

O capitalismo é, provavelmente, a única, ou pelo menos a principal, forma histórica ordenadora de práticas coletivas perfeitamente desvinculadas da esfera moral, no sentido de encontrar sua finalidade em si mesma (a acumulação do capital com fim em si), e não por referência não só ao bem comum, mas também aos interesses de um ser coletivo, tal com povo, Estado, classe social (BOLTANSKI; CHIAPELLO, 2009 p. 53).

Todas as organizações sociais são submetidas ao imperativo de justificação. De acordo com Boltanski e Chiapello (2009), elas tendem a incorporar a referência de um tipo de convenção muito geral, orientada para um bem comum, com pretensão à validade universal. Várias tipologias de cidades são criadas para orientar a análise da justiça nos vários momentos vivenciados pelo capitalismo. Tais imperativos de justificação podem ser modelizados pelo conceito de cidade. 
São identificadas na sociedade contemporânea seis lógicas de justificação, seis cidades. Dois tipos de fontes são utilizados para definir as "grandezas": dados empíricos, colhidos por um trabalho de campo que fornece um corpus de argumentos, e os construtos da filosofia política, que possuem um nível elevado de coerência lógica.

$\mathrm{Na}$ "cidade inspirada", ${ }^{2}$ a grandeza se encontra na distinção do santo que ascende a um estado de graça ou mesmo um artista que recebe inspiração. As manifestações inspiradas são: a santidade, criatividade, senso artístico, autenticidade. Elas constituem a forma privilegiada de expressão. Já na "cidade doméstica", a grandeza das pessoas depende de sua posição hierárquica numa cadeia de dependências pessoais. O grande, nesse caso, é o ancestral, o pai, a quem todos devem respeito e fidelidade. A grandeza só depende da opinião alheia na "cidade da fama", ou seja, da quantidade de pessoas que concedem crédito e estima. $\mathrm{Na}$ "cidade cívica", o grande é o representante de um coletivo cuja vontade geral ele exprime. Na "cidade mercantil, o "grande" é aquele que enriquece colocando no mercado concorrencial mercadorias muito desejadas, ou seja, ele fica rico com o sucesso na prova do mercado. E na "cidade industrial" a grandeza se fundamenta na eficácia e determina uma grandeza de capacidades profissionais. (BOLTANSKI; CHIAPELLO, 2009).

Boltanski e Chiapello (2009) procurarão identificar quais as convenções e modos de referência ao bem comum são tomados de empréstimo pelo terceiro espírito do capitalismo que se encontra atualmente em formação. Os novos discursos justificativos capitalistas não se traduzem em nenhuma das seis cidades. Será necessário propor uma "sétima cidade", que crie equivalências e justifique posições relativas de grandezas num mundo em rede. A base empírica dos autores será um corpus de textos sobre gestão empresarial dos anos 1990, destinados a executivos, material propício para analisar o novo espírito do capitalismo.

Não se evidenciará neste trabalho o que Boltanski e Chiapello (2009) apresentam como o segundo espírito do capitalismo, forma que teve seu pleno desenvolvimento entre os anos 1930 e 1960. Tratava-se de um modelo onde predominava a grande empresa capitalista centralizada e

\footnotetext{
${ }^{2}$ A cidade inspirada foi construída com base na Cidade de Deus de Santo Agostinho e nos tratados por ele dedicados ao problema da graça. A cidade doméstica foi estabelecida por um comentário à Política extraída das próprias palavras da Santa Escritura, de Bossuet. A cidade da fama foi construída a partir do Leviatã, de Hobbes, em especial do capítulo dedicado à honra. A cidade cívica, ou coletiva, é analisada em Do contrato social, de Rousseau. A cidade mercantil é extraída de $A$ riqueza das nações, de Adam Smith. A cidade industrial foi estabelecida a partir da obra de Saint-Simon (BOLTANSKI; CHIAPELLO, 2009, p. 565).
} 
burocratizada, fascinada pelo gigantismo, espaço de organização familiar. A figura do diretor era o principal ícone desse modelo de organização. Acredita-se que para os objetivos propostos no artigo sejam suficientes as ponderações sob a gênese do capitalismo e do seu novo ou terceiro espírito do capitalismo. Após uma passagem pelo primeiro e o "novo" espírito do capitalismo, ver-se-á como Castells (1999) compreende o período por ele denominado "sociedade em rede".

\section{A sociedade em rede}

O final do último século testemunhou a revolução tecnológica concentrada nas tecnologias da informação. Conforme Castells (1999), as mudanças sociais são tão drásticas quanto os processos de transformação tecnológica e econômica. Dentro das inúmeras alterações apresentadas, destaca-se a crise estrutural de legitimidade que os sistemas políticos atravessam. Os movimentos sociais apresentam uma tendência de fragmentação, fenômeno que abre espaço para o reagrupamento em torno de identidades primárias: religiosas, étnicas, territoriais entre outras.

Cada vez mais, as pessoas organizam seu significado não em torno do que fazem, mas com base no que elas são ou acreditam que são. Enquanto isso, as redes globais de intercâmbios instrumentais conectam e desconectam indivíduos, grupos, regiões e até países, de acordo com sua pertinência na realização dos objetivos processados na rede, em um fluxo de decisões estratégicas (CASTELLS, 1999, p. 41).

Em outras palavras, na visão de Castells (1999), nossa sociedade cada vez mais é marca pela oposição bipolar entre a "rede" e o "ser". Ele não compartilha ideias presentes em várias correntes que defendem o niilismo intelectual, ceticismo social e desgraça política. Uma das hipóteses levantadas pelo autor argumenta que todas as mudanças na atualidade são afins e que existe a possibilidade de entender seu inter-relacionamento. Como primeiro passo da investigação, é proposto que a tecnologia seja levada a sério. Ressalta-se a necessidade de localizar o processo de transformação tecnológica revolucionária no contexto social em que ele ocorre e está sendo moldado. "Devido a sua penetrabilidade em todas as esferas da atividade humana, a revolução da tecnologia da informação será meu ponto inicial para analisar a complexidade da nova economia, sociedade e cultura em formação." (CASTELLS, 1999, p. 43). Não se pretende argumentar que a tecnologia determina a sociedade, nem que a sociedade 
escreve o curso da transformação tecnológica - muito embora a sociedade possa refrear o desenvolvimento tecnológico, principalmente através do Estado. Por outro lado, a intervenção estatal pode acelerar a modernização tecnológica e mudar os rumos da economia, do poder militar e do bem-estar social em poucos anos. Em suma, Castells (1999, p. 43) defende que o domínio ou não de aparatos tecnológicos pode determinar a evolução e transformação de uma sociedade:

\begin{abstract}
Assim, quando na década de 1970 um novo paradigma tecnológico, organizado com base na tecnologia da informação, veio a ser constituído, principalmente nos Estados Unidos, foi um segmento específico da sociedade norte-americana, em interação com a economia global e a geopolítica mundial, que concretizou um novo estilo de produção, comunicação, gerenciamento e vida. [...] o grande progresso tecnológico que se deu no início dos anos 70 pode, de certa forma, ser relacionado à cultura da liberdade, inovação individual e iniciativa empreendedora oriunda da cultura dos campi norte-americanos da década de 1960.
\end{abstract}

Para Castells (1999), de forma inconsciente a revolução da tecnologia da informação difundiu na nossa sociedade o espírito libertário dos movimentos dos anos 1960. Porém, após a propagação, os valores foram difundidos por diferentes países, diversas culturas. $O$ resultado foi que as novas tecnologias da informação foram aplicadas e utilizadas de inúmeras formas.

A reestruturação do sistema capitalista a partir da década de 1980 em grande medida foi condicionada pela revolução na tecnologia da informação. Nesse cenário, Castells (1999) se propõe estudar o surgimento de uma nova estrutura social, associada ao surgimento de um novo modelo de desenvolvimento, o "informacionismo", que se manifestou sob várias formas moldado pela diversidade de culturas e instituições em todo o planeta.

Em síntese, Castells (1999) acredita que várias reformas, tanto no domínio das instituições como no gerenciamento empresarial, visaram a atingir quatro objetivos principais. O primeiro seria aprofundar a lógica capitalista com o intuito de alcançar maior lucratividade. Segundo, aumentar a produtividade do trabalho e do capital. A globalização da produção, maior circulação nos mercados, seria o terceiro objetivo. Quarto, o direcionamento do apoio estatal para elevação dos ganhos de produtividade e competitividade das economias nacionais.

Podemos dizer que, se no primeiro espírito do capitalismo a "inovação" sofreu implacável resistência diante um tradicionalismo enraizado na própria 
estrutura do Estado, na nova estrutura social as redes se constituem um sistema aberto dinâmico, cuja inovação não aparece mais como uma ameaça ao equilíbrio, mas como seu próprio motor.

\section{Convergência e aproximações metodológicas entre as abordagens}

Se colocados em comparação - o "novo espírito do capitalismo" e a "sociedade em rede" -, é possível verificar complementaridades. O último, de forma exaustiva apresenta um conjunto dados e informações de considerável número de países para comprovar a ocorrência de mudanças estruturais na sociedade contemporânea. Já o primeiro analisa o conteúdo dessa mudança de forma mais qualitativa. Possivelmente tal objetivo não teria sido alcançado sem a restrição da análise ao espaço francês, o que não invalida a capacidade analítica desta pesquisa.

A abordagem de Boltanski e Chiapello (1999) se distancia da tentativa de explicar a gênese do capitalismo. O objetivo é entender como na atualidade o sistema recruta os atores necessários para a formação do lucro. Por outro lado, os autores adotam o método do tipo ideal weberiano para captar as variações que o capitalismo atravessou nos últimos trinta anos e entender os traços ideológicos específicos que caracterizam a nova representação do sistema. Diferente de Castells (1999), Boltanski e Chiapello (2009) não usam fontes estatísticas. A ideia foi resgatar a literatura sobre a gestão empresarial destinada a executivos, tendo em vista que se trata de um dos principais espaços de inscrição do espírito do capitalismo. A literatura de gestão empresarial, que não é puramente técnica, além de receitas para melhorar o desempenho das organizações, também é carregada de um forte conteúdo moral. Segundo os autores, os textos são como o exemplum que deve ser seguido, ou virtudes que devem ser praticadas.

A intenção de Castells (1999) não é fazer um livro sobre livros; seu argumento defende que já existe um bom conjunto de teorias sobre sociedade da informação, pós-industrialismo, pós-modernidade, entre outros temas contemporâneos. A proposta é construir um discurso que integre matérias e observações de diversas fontes. É considerável a quantidade de informações apresentadas na obra - os dados vão desde estatísticas da ONU e do Banco Mundial até as monografias acadêmicas e empresariais. A ideia do autor é utilizar um corpus de observações selecionadas para posteriormente sugerir hipóteses. Segundo ele, a metodologia utilizada no estudo: 
[...] está a serviço do objetivo abrangente de seu empenho intelectual: propor alguns elementos de uma teoria transcultural exploratória da economia e da sociedade na Era da Informação, no que se refere especialmente ao surgimento de uma nova estrutura social (CASTELLS, 1999, p. 61).

O tamanho da obra de Castells é proporcional à penetrabilidade do informacionalismo em todos os domínios sociais e culturais. Exagerando na mão, arrisco-me a dizer que a principal preocupação de Boltanski e Chiapello (2009) foi entender a "alma" ou o novo "espírito" do capitalismo. Já Castells (1999) se propõe a desvencilhar a configuração que este novo "corpo" social, econômico e cultural adquiriu, ou seja, os contornos e as formas assumidas pela sociedade em rede.

\section{Poder na estrutura de rede}

O conhecimento e a informação sempre foram elementos importantes em todas as formas de desenvolvimento, tendo em vista que o processo de produção em grande medida está ancorado no conhecimento e no processamento da informação. "[...] o que é específico ao modo informacional de desenvolvimento é a ação de conhecimentos como principal fonte de produtividade." (CASTELLS, 1999, p. 54). Posição semelhante é defendida por Boltanski e Chiapello (2009, p. 104): na análise dos discursos empresariais, é colocado em primeiro plano "[...] a importância da informação como fonte de produtividade e lucro". A partir do estudo do caso francês os autores ressaltam que no mundo em rede há uma correlação direta entre capital social e capital informacional. Isso quer dizer que a informação é ao mesmo tempo resultado e condição para multiplicação de conexões, de tal maneira que a desigualdade de informação é cumulativa. "O grande" da cidade dos projetos deve distribuir com sua equipe os bens raros aos quais têm acesso, e o bem mais importante que ele possui é a informação.

Se no industrialismo o importante é o crescimento da economia e a maximização da produção, no informacionalismo o principal aspecto é o desenvolvimento tecnológico, ou seja, a acumulação de conhecimento em níveis mais elevados de complexidade no processamento. Castells (1999) acredita que embora o novo paradigma da informação seja originário das esferas dominantes da sociedade, ele se difunde para todas as estruturas socais.

As estruturas da sociedade em rede em Castells (1999) são abertas e capazes de se expandir de forma ilimitada, integrando infinitos nós à rede. 
Por outro lado, a sua incorporação à rede depende da capacidade desses atores de se comunicar em seu interior. As configurações de poder no interior da rede também se evidenciam no momento em que nem todos são capazes de compartilhar os códigos de comunicação dominante. A incapacidade de "falar a mesma língua" pode impedir a expansão da rede. 0 próprio Castells (1999, p. 564) ressalta que "o poder dos fluxos é mais importante que os fluxos de poder". Portanto, a presença ou ausência das redes não pode se transformar em fonte de dominação ou transformação social.

\title{
O tempo como variável central para entender o espírito do capitalismo
}

As especificidades do capitalismo ao longo dos tempos podem ser evidenciadas pela forma como o tempo é utilizado, com vista à conquista ou a atingir determinado objetivo. Weber (2004) apresenta, nas palavras de Benjamin Franklin, a definição pura do que seria o primeiro espírito do capitalismo - nele o tempo aparece como uma variável-chave:

\begin{abstract}
Lembra-te, tempo é dinheiro; aquele que com seu trabalho pode ganhar dez xelins ao dia e vagabundeia metade do dia, ou fica deitado em seu quarto, não deve, mesmo que gaste apenas seis pence para se divertir, contabilizar só essa despesa; na verdade gastou, ou melhor, jogou fora, cinco xelins a mais (WEBER, 2004, p. 42-43).
\end{abstract}

Observa-se que no fundo as advertências morais são de cunho utilitário, virtudes que de forma despretensiosa ou não intencional formaram a base do capitalismo ocidental. Na cidade dos projetos de Boltanski e Chiapello (2009) o tempo também é um bem raro. "O grande" nessa cidade é aquele capaz de otimizar o uso desse recurso escasso, principalmente escolhendo com discernimento as relações que devem ser mantidas, evitando conectar-se a pessoas próximas ou àquelas que propiciam somente prazer de ordem afetiva ou lúdica.

$\mathrm{Na}$ visão de Castells (1999), a personificação do tempo é uma marca da nossa sociedade. Trata-se de uma categoria que é central no debate da teoria social. No atual contexto se verifica o que se poderia chamar de "tempo intemporal" - trata-se de uma forma dominante emergente na sociedade em rede. Castells (1999, p. 536) se aproxima de Boltanski e Chiapello (2009) ao dizer "O que está em jogo e parece ser a tendência predominante na maioria dos setores avançados da maior parte das 
sociedades desenvolvidas é a diversificação geral do tempo de trabalho". Como foi possível observar, as concepções de tempo estão intimamente ligadas à forma como o poder é exercido dentro do sistema capitalista.

As palavras de Benjamin Franklin expressam que tempo é algo valioso; horas desperdiçadas são horas perdidas de trabalho. $O$ crente ascético estava liberto dos entraves tradicionais que condenavam o enriquecimento. $\mathrm{O}$ acúmulo de bens materiais como fruto do trabalho passou a ser algo bem-visto por Deus. A única advertência era sobre a má utilização da riqueza em uma vida ociosa e de prazeres. A preguiça, perda de tempo e o consumo supérfluo são os pecados por excelências. Em outras palavras, para um calvinista, desejar ser pobre é a mesma coisa que desejar ser doente; sua prática ascética estava ancorada na produção de riqueza privada. Boltanski e Chiapello (2009) destacam que no mundo em rede o senso de poupança não desapareceu, mas não é mais o principal meio de promoção social como foi no primeiro espírito do capitalismo. Na sociedade em rede, ganha força a possibilidade de locação ou empréstimo. O que importa agora é a disponibilidade. "O homem ajustado a um mundo conexionista preferirá, por exemplo, alugar a residência principal, pois ele é levado a mudar-se frequentemente..." (BOLTANSKI; CHIAPELLO, 2009, p. 191). A constituição de uma nova "Era do Acesso" é proposta por Rifkin (2005). Segundo ele, os conceitos de guardar e acumular estão ficando obsoletos, pois em uma sociedade na qual as inovações tecnológicas estão ocorrendo em ritmo cada vezes mais intenso a ideia de propriedade passa a ser bastante problemática. No mundo das cidades dos projetos, as pessoas dispõem dos bens durante o tempo que lhes convêm. O poder de coerção da posse da propriedade é substituído pelo acesso fácil e temporário dos recursos locados.

A análise realizada por Weber (2004) é centrada na ação social do capitalista, ou seja, em sua conduta dotada de sentido racional. O éthos da conduta do mesmo influenciou de forma decisiva a estrutura de organizações do capitalismo nascente. O controle do tempo, a vigilância, a disciplina na realização de todas as funções, a separação entre o tempo da fábrica e o tempo de lazer, entendendo o lazer como período de descanso funcional para uma maior produtividade no ambiente de trabalho. De acordo com essas características, as organizações do primeiro espírito capitalista em Weber (2004) se aproximam da "sociedade disciplinar" de Foucault (1996), constituída por grandes meios de confinamento, tendo como características principais a distribuição de indivíduos em espaços individualizados, hierarquizados e classificatórios. Em síntese, busca estabelecer uma sujeição do indivíduo ao tempo com a pretensão de tornar 
seu trabalho o mais eficaz possível. A análise de Boltanski e Chiapello (2009, p. 102-103) aponta que a empresa que caracteriza a cidade dos projetos é pensada como uma empresa enxuta - na sua estrutura não há mais um grande número de escalões hierárquicos: "[...] a imagem típica da empresa moderna hoje em dia é de um núcleo enxuto rodeado por uma miríade de fornecedores, serviços terceirizados, prestadores de serviços e trabalhadores temporários..." Os trabalhadores não estão mais inseridos em uma estrutura inflexível; eles se organizam em pequenas equipes pluridisciplinares, a figura do chefe é substituída por um coordenador. Agora os membros da equipe não precisam ficar presos ao mesmo espaço físico vigiado por um "panóptico", para utilizar o termo de Jeremy Bentham. O trabalho se dá em rede, ancorado pelos grandes avanços nas tecnologias de telecomunicações.

\section{Considerações finais}

Boltanski e Chiapello (2009) são otimistas em relação à capacidade de expansão do modelo conexionista. Mesmo observando os territórios que se encontram no centro das inovações e transformações do capitalismo, em grande medida eles acreditam que as mudanças atingem todo o globo. Não seria miopia acreditar que a "labuta" diária característica do primeiro espírito do capitalismo foi substituída na maioria das nações por um novo espírito que valoriza a "atividade" profissional que mistura atividade profissional, lúdica e pessoal. Faz parte do cotidiano da maioria dos trabalhadores dos países periféricos do capitalismo formas de remuneração, tais com honorários, direitos autorais, royalties? Ou, quando não estão em plena informalidade, o modo mais característico de remuneração é o assalariamento em tempo integral que, segundo Boltanski e Chiapello (2009, p. 193), é a característica presente na gênese do capitalismo. Poder-se-ia dizer que a tipologia do primeiro espírito do capitalismo não se encontra totalmente extinta. Umas das explicações é que os diversos países não estão no mesmo momento, ou melhor, não partilham do mesmo espírito do capitalismo. Essas ponderações não visam a questionar o poder explicativo de tais teorias para fenômenos que são emergentes em nosso tempo, porém é necessário ponderar a intensidade e as abrangências das transformações. A difusão do informacionalismo para Castells (1999) é inseparável da reestruturação do capitalismo em escala global. No entanto, a reação de cada sociedade a essas mudanças não tem sido homogênea; cada sociedade possui uma especificidade histórica, cultura e instituições diferentes.

A ideia da constituição de redes técnicas, como o caso do surgimento da internet, descrito por Castells (1999), pode ser imaginada de forma 
semelhante às redes empresariais e suas práticas adotadas nas últimas décadas. A "metáfora da rede", longe de se limitar a uma visão pejorativa, de redes de corrupção, narcotráfico, prostituição, entre outras, é resgatada para apresentar um novo "espírito do capitalismo". O novo espírito é capaz de absorver críticas de diversas naturezas e conquistar para sua estrutura parte importante daqueles que o contestavam. Várias mudanças foram percebidas, como a flexibilização produtiva e a constante promessa de mobilidade dos seus trabalhadores. A sociedade que emerge no final do século XX para Castells (1999) foi descrita como uma "rede", ou seja, um conjunto de nós interconectados que podem expandir de forma ilimitada. A nova morfologia social pode modificar de forma substancial os resultados dos processos produtivos e as experiências sociais e culturais.

\section{Referências}

BOLTANSKI, LUC; CHIAPELLO, ÈVE. 2009. O novo espírito do capitalismo. São Paulo: Editora WMF Martins Fontes.

CASTELLS, Manuel. 1999. A sociedade em rede. São Paulo: Paz e Terra.

FOUCAULT, Michel. 1996. Vigiar e punir: nascimento da prisão. Petrópolis: Vozes.

GIDDENS, Anthony. 1990. Capitalismo e Moderna Teoria Social. Lisboa: Editora Presença.

REEBER, Michel. Religião: termos, conceitos e ideias. Rio de Janeiro: Ediouro, 2002.

RIFKIN, Jeremy. 2005. A era do acesso. São Paulo: Editora Makron.

WEBER, Max. 2004. A ética protestante e o "espírito" do capitalismo. São Paulo: Companhia das Letras. . 1999. Economia e sociedade (Volume I): fundamentos da sociologia compreensiva. Brasília (DF): Editora Universidade de Brasília. 